\title{
MONITORING OF HISTORICAL MASONRY STRUCTURES WITH OPERATIONAL MODAL ANALYSIS: TWO CASE STUDIES
}

\begin{tabular}{|c|c|c|}
\hline Luís Ramos, & University of Minho, Dep. Civil Engineering, & Portugal \\
\hline Leandro Marques, & University of Minho, Dep. Civil Engineering, & Portugal \\
\hline Paulo Lourenço, & University of Minho, Dep. Civil Engineering, & Portugal \\
\hline Guido De Roeck, & K.U. Leuven, Department of Civil Engineering, & Belgium \\
\hline Alfredo Campos-Costa & Laboratório Nacional de Engenharia Civil, & Portugal \\
\hline João Roque, & Polytechnic Institute of Bragança, & Portugal \\
\hline
\end{tabular}

\begin{abstract}
Two monuments in Portugal are being monitoring by the University of Minho: the Clock Tower of Mogadouro and the Church of Jerónimos Monastery, in Lisbon. Vibration sensors and temperature and relative air humidity sensors are installed in the two monuments. Operational modal analysis is being used to estimate the modal parameters, followed by statistical analysis to evaluate the environmental effects on the dynamic response. The aim is to explore damage assessment in masonry structures at an early stage by vibration signatures as a part of a heath monitoring process to preserve the historical constructions. The paper presents all the preceding dynamic analysis steps before the monitoring task, which includes the installation of the monitoring system, the system identification and subsequent FE model updating analysis, the automatic modal identification and the investigation of the influence of the environment on the identified modal parameters.
\end{abstract}

\section{Introduction}

Preservation of the architectural heritage is considered a fundamental issue in the cultural life of modern societies. Modern requirements for an intervention include reversibility, unobtrusiveness, minimum repair and respect of the original construction, as well the obvious functional and structural requirements.

The present paper tries to deal with the problem of damage identification by using Global and Local damage identification techniques. It is advantageous to have two categories of damage assessment methods: (a) the vibration based damage identification methods, currently defined as Global methods, they can alert the presence of damage and define its location (e.g. [1]), but they do not give sufficiently accurate information about the type and the detailed definition of the damage; and (b) the visual inspections or experimental ND tests like acoustic or ultrasonic methods, magnetic field methods, radiograph, eddy-current methods and thermal field methods (e.g. [2]), also called as Local methods, they can be preceded by the global approach (Global method) to detect and localize the damage, and then, if the possible location of damage is accessible in the structure, they can describe the damage in an accurate way. 


\section{Damage in Masonry Structures}

The damage on masonry structures mainly relates to cracks, foundation settlements, material degradation and deformations. When the cracks occur, generally they are localized, splitting the structures in macro-blocks. The use of dynamic based methods to assess the damage is an attractive tool to apply on this type of structures due to the present requirements of unobtrusiveness, minimum physical intervention and respect of the original construction. The assumption that damage can be linked to a decrease of stiffness seems to be reasonable to this type of structures.

Many methods are presented in literature, see [3] and [4], for damage identification based on vibration signatures but there are only a few papers on the application to masonry like structures. An important task before damage can be identified from vibration characteristics, is the study and subsequent elimination of the environmental effects [5].

\section{Monitoring Procedures}

The current practices of structural health condition are based mainly on periodic visual inspections or condition surveys but, during the last decade, software and hardware developments made continuous monitoring possible nowadays [4]. Typically, one can install hundreds of sensors in a structure and read the data in real time. The attention now is focused on the following aspects: what type of information is important from the structural point of view and how the data should be processed and stored for damage analysis [6]. The developments in MEMS and WSN are promising technologies in this field, in particular for historical masonry structures.

Concerning monitoring of historical masonry structures, this task can be divided in four phases:

1. The first phase is the data collection of the structure, including the historic information, geometrical and topographic survey, damage survey, the mechanical materials characterization with ND tests, a global dynamic modal test and a numerical model analysis for static and dynamic calibration. This is the first approach to the structural behaviour in the assumed healthy condition at time "zero";

2. In the second phase the health monitoring plan can be performed with a limited number of sensors (e.g. a pair of reference accelerometers, strain gauges at critical sections, temperature and humidity sensors, etc). Data should be stored periodically and the monitoring system should be able to send the proper alarms. Environmental effects should be studied and the presence of damage should be observed by the global modal parameters;

3. In the third phase, after alarm triggering, a full-scale dynamic survey with more sensors and measuring points should be performed. In this phase the "health condition" of a structure is studied with more detail. Damage identification methods should be applied to the structure after filtering the environmental effects. The aim of the dynamic methods is to confirm and locate the (possible) damage in a global way;

4. In the last phase, a local approach with visual and complementary ND tests should be performed to locally assess the damage and classify it. This can be carried out with sonic test or radar tests, depending on the access conditions of the structure. This local approach can give a better definition of the damage.

The global and local approach should be considered as complementary tasks. For the case of historical constructions these two approaches seem to be suitable, since they are ND procedures to 
evaluate the health conditions. The following sessions present two case studies of the University of Minho, where the first two phases of the preceding methodology were already applied.

\section{Case Study I - Mogadouro Clock Tower}

The Mogadouro Clock Tower is located inside the castle perimeter (see Figure 1) of Mogadouro, a small town in the Northeast of Portugal. The tower was built after the year 1559. It has a rectangular cross section of $4.7 \times 4.5 \mathrm{~m}^{2}$ and a height of $20.4 \mathrm{~m}$. It was built in masonry (granite stones) with dry joints in the corners and mortar joints in the middle of the walls. The walls have, on average, $1 \mathrm{~m}$ of thickness.

In 2004, severe damage was observed in the tower, characterized by cracks, material degradation and losses of material in some parts, see Figure 1. A geometrical survey of the structure was performed by photogrammetry and all anomalies were reported in a structural survey.

The rehabilitation works carried out in 2005 established again the tower structural safety. In the treatment were included: injection for the walls consolidation, replacement of materials with high level of degradation and the installation of tie-rods at two levels.

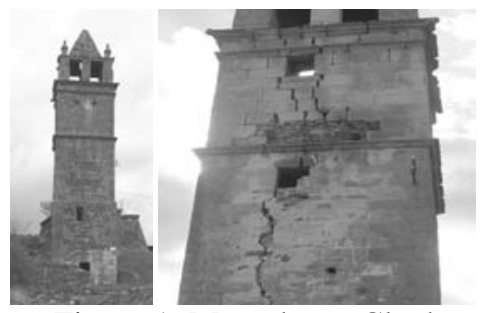

Figure 1: Mogadouro Clock Tower: general view and severe damage before rehabilitation

\subsection{Modal Identification Before and After the Rehabilitation Works}

Two dynamic modal identification tests were performed before and after the structural rehabilitation. Operational modal analysis was used to estimate the modal parameters. Figure 2 presents some images of the ambient dynamic tests.
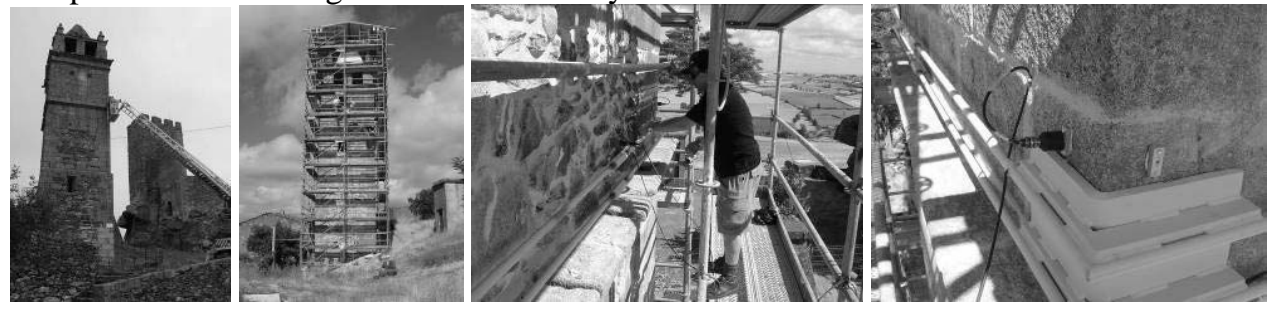

Figure 2: Measurements before and after the rehabilitation showing also some sensor locations

Table 1 presents the first five estimated natural frequencies, damping ratios and MAC values and Figure 3 shows the corresponding mode shapes after rehabilitation.

\begin{tabular}{cccccc}
$\begin{array}{c}\text { Mode } \\
\text { Shape }\end{array}$ & \multicolumn{2}{c}{$\begin{array}{c}\text { Frequency } \\
{[\mathrm{Hz}]}\end{array}$} & \multicolumn{2}{c}{$\begin{array}{c}\text { Damping } \\
{[\%]}\end{array}$} & MAC \\
& Before & After & Before & After & \\
\hline $1^{\text {st }}$ & 2.15 & 2.56 & 2.68 & 1.25 & 0.86 \\
$2^{\text {nd }}$ & 2.58 & 2.76 & 1.71 & 1.42 & 0.84 \\
$3^{\text {rd }}$ & 4.98 & 7.15 & 2.05 & 1.16 & 0.83 \\
$4^{\text {th }}$ & 5.74 & 8.87 & 2.40 & 1.27 & 0.26 \\
$5^{\text {th }}$ & 6.76 & 9.21 & 2.14 & 1.16 & 0.51 \\
\hline
\end{tabular}

Table 1: Experimental results

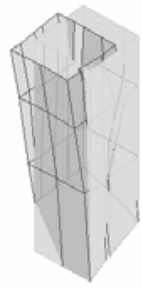

Mode 1

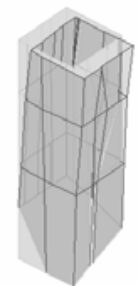

Mode 2 Mode 3
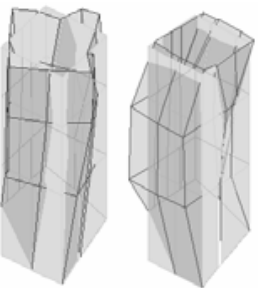

Mode 4 Mode 5

Figure 3: Experimental modes shapes

From the comparison between the modal parameters before and after the rehabilitation is possible to observe an increase of $40 \%$, on average, for the frequency values and a decrease of $50 \%$, on 
average, for the damping values. The MAC values are less than 0.86 , indicating that the repair operations clearly altered the stiffness distribution and so the mode shapes.

\subsection{Structural Assessment}

For the structural assessment, a FE model was built will shell elements. A model updating analysis was performed with the aim to assess the tower dynamic behavior in its actual condition (after the retrofitting). The nonlinear least square method implemented in MatLab was used together with DIANA to compute the numerical modes. The objective function $\pi$ to be minimized is composed by the residuals formed with calculated and experimental frequencies and mode shapes, given by:

$$
\pi=\frac{1}{2} \sum_{j=1}^{m}\left[\left(\frac{\omega_{j}^{2}-\omega_{j, \text { exp }}^{2}}{\omega_{i, \text { exp }}^{2}}\right)^{2}+\left(\varphi_{j}-\varphi_{j, \exp }\right)^{2}\right]
$$

where $m$ denotes the number of modes $(m=5)$. In Eq.(1) both experimental and numerical modes are normalized in a way that the maximum real value of the modal displacements is equal to 1 .

The selection of the optimization parameters was done taking into account the geometrical survey of the tower and the possible differences between the material properties. Five modulus of elasticity according to the distribution of Figure 4 were tuned. The updated values are presented in Figure 4. Figure 5 shows the results in terms of mode shapes. The frequency errors were lower that $3.2 \%$ and the MAC values better than 0.98. Another updating analysis is being performed for the damage condition to evaluate the level of damage and the effectiveness of the rehabilitation works.

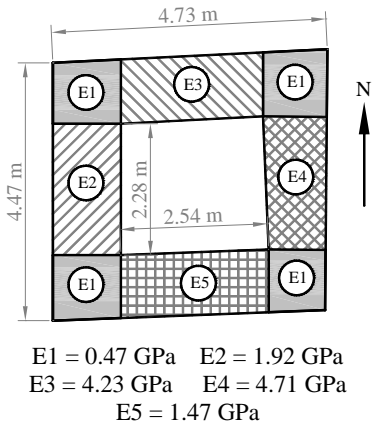

Figure 4: Updating Parameters

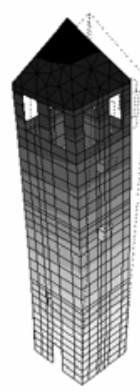

Mode 1

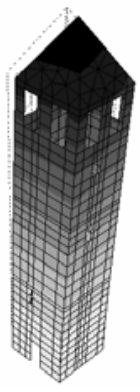

Mode 2

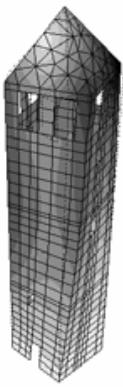

Mode 3

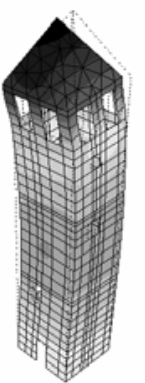

Mode 4

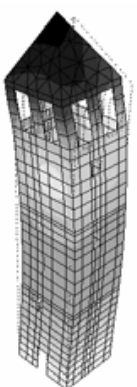

Mode 5

Figure 5: Numerical updated modes shapes

\subsection{Dynamic Monitoring System}

From the beginning of April 2006, so after the rehabilitation, a dynamic monitoring system was installed in the tower, see Figure 6. The aim is to evaluate the environmental effects of temperature and relative air humidity on the dynamic behaviour of the tower, and to detect any possible non stabilized phenomena in the structure (damage).
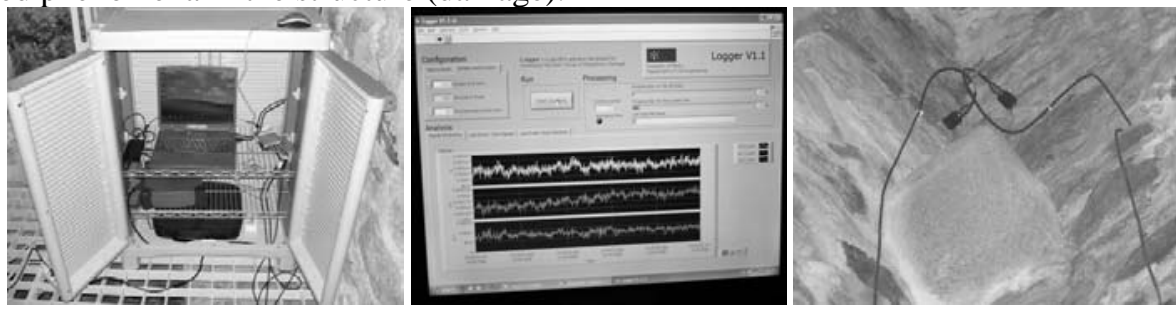

Figure 6: Dynamic monitoring system: datalogger, acquisition software and accelerometers 
Three piezoelectric accelerometers connected to an USB data acquisition card with 24 bits resolution are recording each hour $10 \mathrm{~min}$ of ambient vibrations. In parallel a combined sensor is recording the ambient temperature and relative air humidity. The monitoring task is performed in several campaigns (test series) during the year. During each campaign 600 records of 10 min at every hour are stored in a laptop. No triggering was applied. Until this moment 6 series were completed in the period from April 2006 till January 2007.

For modal estimation, an automatic procedure based on SSI/Ref method [7] was implemented in MatLab. After a manual identification with a few data files, eigenfrequency intervals, damping intervals and a reference mode shape vector were established. For every event data, the selection of the model order in the stabilisation diagrams was performed according to the expected intervals and the best MAC value (always greater than 0.95).

\subsection{Environmental Effects}

The preliminary results for the first two modes are presented in Figure 7, in terms of frequency variation according to temperature and relative air humidity. One conclusion emerged from the results is the structure sensibility to the relative air humidity (or the water absorption by the masonry material due to the raining season). As no damage was observed in the structure, the humidity influence can be observed by a shift of $4 \%$ in the linear relation between frequency and temperature by a transitory series (gray dots in the left part of Figure 7). This series was recorded between November and October, 2006 which was the first raining period at the site.
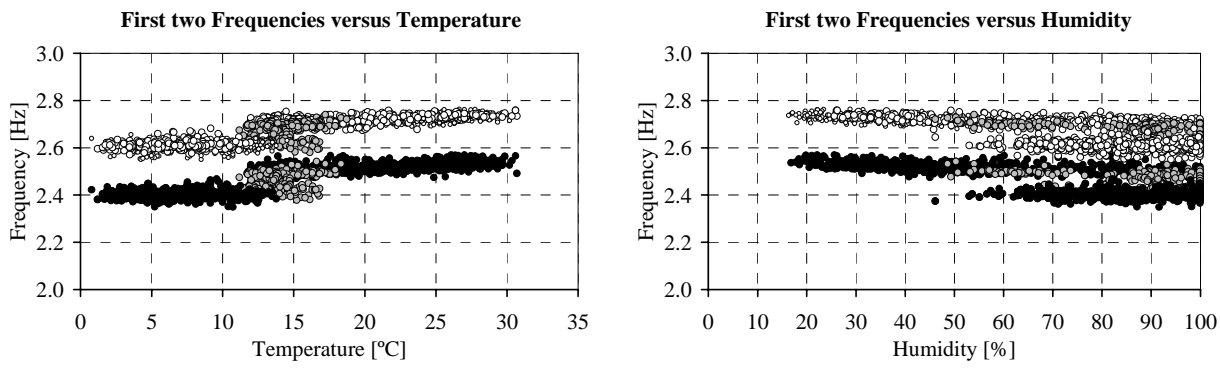

Figure 7: Environmental effects: temperature and relative air humidity

Since the structure seems to be sensitive to the humidity, it is necessary to have a complete cycle of one year to model the environmental effects. Especially, the new heating season, where the drying phenomena in the material are expected to reestablish the initial frequency values, should be included.

\section{Case Study II - Church of Monastery of Jerónimos}

The Monastery of Jerónimos, located in Lisbon, is one of the most famous Portuguese monuments (see Figure 8). The authentic Portuguese "Manuelino" architectural style of the XVI Century makes the monument very attractive for tourists. The church of the monastery, Santa Maria de Belém church, has considerable dimensions: a length of $70 \mathrm{~m}$, a width of $40 \mathrm{~m}$ and a height of $24 \mathrm{~m}$

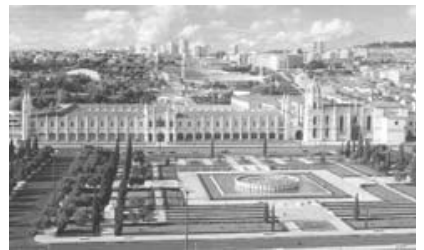

Figure 8: Monastery of Jerónimos

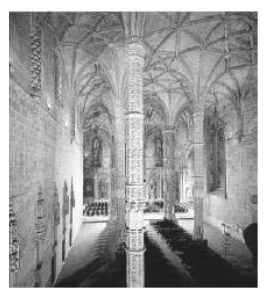

Figure 9: Church (see Figure 9). 


\subsection{Modal Identification of the Main Nave}

Table 2 summarizes eight natural frequencies, damping ratios and MAC values estimated by two different output-only system identification techniques. The natural frequencies range from 3.7 to $15.1 \mathrm{~Hz}$ and no significant differences could be found between the two methods. For the damping coefficients, differences up to $140 \%$ can be observed. The MAC values are only higher than 0.95 for the first two modes as a consequence of the difficulty in exciting this heavy structure.

\begin{tabular}{cccccc}
$\begin{array}{c}\text { Mode } \\
\text { Shape }\end{array}$ & \multicolumn{2}{c}{$\begin{array}{c}\text { Frequency } \\
{[\mathrm{Hz}]}\end{array}$} & \multicolumn{2}{c}{$\begin{array}{c}\text { Damping } \\
{[\%]}\end{array}$} & MAC \\
& EFDD & SSI & EFDD & SSI & \\
\hline $1^{\text {st }}$ & 3.69 & 3.68 & 2.34 & 1.26 & 0.99 \\
$2^{\text {nd }}$ & 5.12 & 5.04 & 1.11 & 2.68 & 0.92 \\
$3^{\text {rd }}$ & 6.29 & 6.30 & 1.00 & 0.82 & 0.67 \\
$4^{\text {th }}$ & 7.23 & 7.29 & 0.77 & 1.44 & 0.67 \\
$5^{\text {th }}$ & 9.67 & 9.65 & 1.10 & 1.45 & 0.62 \\
$6^{\text {th }}$ & 11.64 & 11.65 & 1.20 & 1.46 & 0.36 \\
$7^{\text {th }}$ & 12.45 & 12.51 & 1.25 & 1.19 & 0.71 \\
$8^{\text {th }}$ & 14.99 & 15.09 & 1.31 & 2.77 & 0.49 \\
\hline
\end{tabular}

Table 2: Experimental results
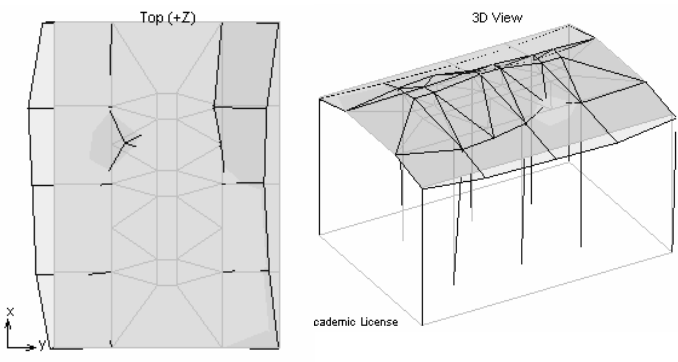

Figure 10: First experimental mode shape

Figure 10 shows the shape of the first mode. The dynamic response of the main nave is influenced by the slenderness of the columns. The mode are essentially composed by components in y (northsouth) and z (vertical) directions.

Nevertheless, this modal identification seems to be acceptable if the structural complexity of the main nave is taking into account. Even if the mode shape and damping coefficients estimation is not very accurate for the higher modes, their natural frequencies were accurately extracted by the two experimental techniques.

\subsection{Structural Assessment}

Due to the high level of complexity of the structure a beam FE model was manually tuned to the dynamic experimental results. The updating parameters were the modulus of elasticity of the columns and the main nave and the boundary conditions of the columns. The dynamic response is most governed by the slender columns, as many local modes appear in the results. The first mode shape of the numerical model is presented in Figure 11. Table 3 shows the first eight frequencies after tuning for the first frequency. The results obtained for the modulus of elasticity were $30 \mathrm{GPa}$ for the columns and $12 \mathrm{GPa}$ for the masonry. The high value for the columns can be explained by the higher compression stresses that are present due to the reduced cross section.

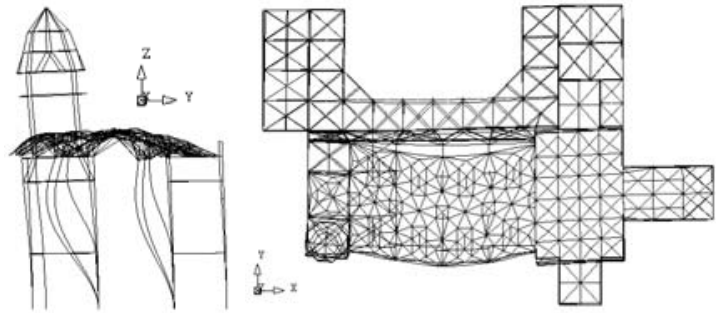

Figure 11: First numerical mode shape

\begin{tabular}{ccc} 
Modes & $\begin{array}{c}\text { Frequency } \\
{[\mathrm{Hz}]}\end{array}$ & Comment \\
\hline 1 & 3.79 & Main nave (y ) \\
2 & 5.06 & Tower (y) \\
3 & 5.20 & Tower (x) \\
\hline 4 & 5.34 & Columns and main \\
5 & 5.76 & nave (y) \\
6 & 6.13 & Columns and main \\
\hline 7 & 6.23 & nave(x) \\
8 & 6.32 &
\end{tabular}

Table 3: Numerical Results

\subsection{Dynamic Monitoring System}

Since April of 2005, a dynamic monitoring system was installed in the church in the scope of the Euro-Indian research project "Improving the Seismic Resistance of Cultural Heritage Buildings". 
The system is composed by two strong motions recorders with 18 bits AD converters connected to two triaxial force balance accelerometers. One accelerometer (A1) was installed on the base of the structure near the chancel and the other (A2) on the top of the main nave (extrados), between two consecutive columns and in the locations with higher signal levels in the dynamic modal identification analysis.

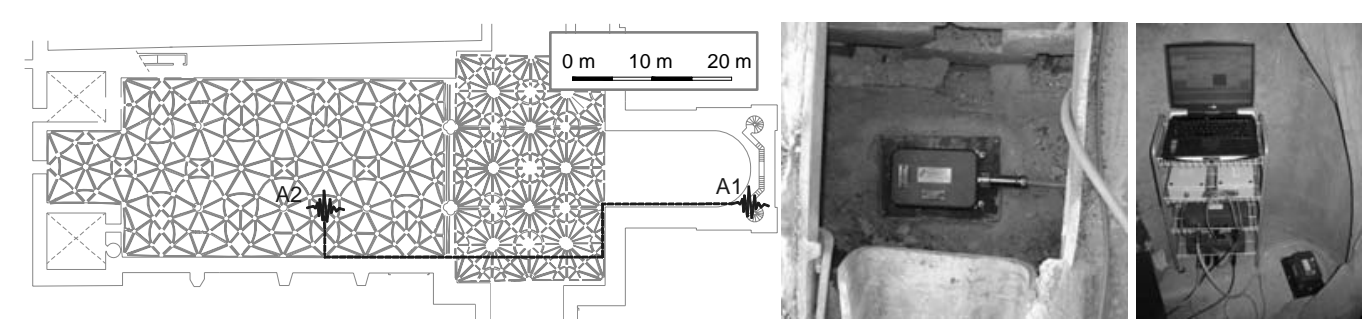

Figure 12: Dynamic monitoring system: location of the sensors; accelerometer on the main nave, and battery of recorders together with the base accelerometer

The two recorders are connected by an enhanced interconnection network, which allows a common trigger and time programmed records. The recorder connected to sensor A1 is the master recorder: it enables the synchronization and updates the internal clock of the slave recorder connected to sensor A2.

The monitoring task is mainly processed by the master recorder which trigger is armed for low level signals corresponding to micro tremors occurring at the site. In parallel, every month, data are registered during 10 minutes. Also seasonally, to study the environmental effects, 10 minutes are recorded every hour during one complete day.

The dynamic monitoring system is complemented by a static one, which measures temperatures at several points in the structure. For the moment, additional sensors for relative air humidity and wind velocity are added to the observation system, especially to study the influence of humidity.

\subsection{Environmental Effects}

With the same procedure for parameters estimation as presented in Section 4.3, more than 1000 records were analyzed. The results for the first frequency are summarized in Figure 13 and Figure 14. In the last one, it is possible to observe an apparent quadratic relation between frequency and temperature. For this dependency the 98\% confidence intervals were established, which can be used, for future results, as borders defining the domain of significant frequency shifts (so

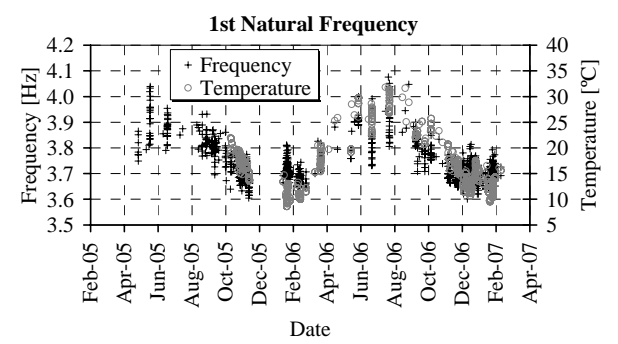

Figure 13: Environmental effects indicating possible damage).

For increased reliability, the model still has to be updated by considering another hot period together with humidity information. 

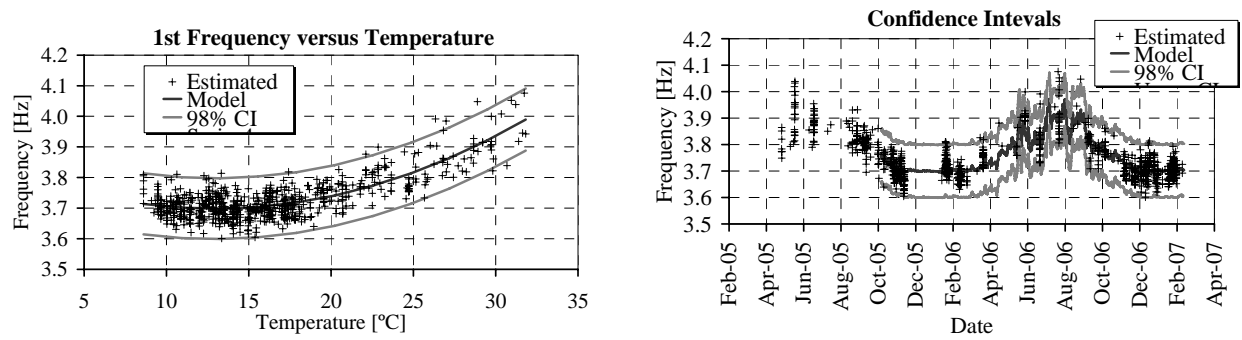

Figure 14: Quadratic regression and confidence intervals

\section{Conclusions}

A methodology based on operational modal analysis is presented for masonry structures, aiming to detect damage at an earlier stage. The methodology comprises four phases.

As an illustration, the first two were applied to two Portuguese monuments. For these monuments, the modal identification results, the structural assessment with FE models and updating techniques, the installation of the monitoring systems and the automatic parameter retrieval were presented.

Finally, a first study of the environmental effects on the dynamic behaviour was made. An important conclusion emerging from the results is the non negligible influence of the humidity on the dynamic behaviour of masonry like structures.

\section{Acknowledgments}

The authors would like to thank Edwin Reynders for his kind support in the automatic system identification task.

\section{References}

[1] P.C. Chang, A. Flatau, S.C. Liu, "Review Paper: Health Monitoring of Civil Infrastructure”, Structural Health Monitoring, Vol. 2 (3), pp. 257-267 (2003)

[2] J.E. Doherty, “Nondestructive Evaluation, Handbook on Experimental Mechanics”, A.S. Kobavashi Edt., Society for Experimental Mechanics, Chapter 12 (1987)

[3] S.W. Doebling, C.R. Farrar, M.B Prime, D. Shevitz, "Damage identification and health monitoring of structural and mechanical systems from changes in their vibration characteristics: a literature review”, Los Alamos National Laboratory, NM (1996)

[4] J. Maeck, "Damage Assessment of Civil Engineering Structures by Vibration Monitoring”, PhD Thesis, Catholic University of Leuven, Belgium (2003)

[5] B. Peeters, "System Identification and Damage Detection in Civil Engineering", PhD Thesis, Catholic University of Leuven, Belgium (2000)

[6] N.A. Londoño, "Use of Vibration Data for Structural Health Monitoring of Bridges”, PhD Thesis, Carleton University, Ottawa, Canada, (2006)

[7] B. Peeters, G. Roeck, "Reference-based stochastic subspace identification for output-only modal analysis”, Mechanical Systems and Signal Processing, 13(6) pp. 855-878 (1999) 